\title{
Eficácia do direito ao lazer do professor: elemento pa- ra manutenção da ordem econômica brasileira
}

\author{
Effectiveness of the law professor of leisure: element for \\ maintenance of Brazil's economic order
}

\section{Marcela Andressa Semeghini Pereira}

Mestranda em Direito pela Universidade de Marília - UNIMAR. Rua Antonio Alpino, 270, Jardim América, Marília, São Paulo CEP 17505-240; telefones (14) 3413-7509 ou 99701 7922. Marília, SP-Brasil, e-mail: masemeghini@bb.com.br

\section{Resumo}

Este artigo investigou a precarização do trabalho docente, com foco no ensino superior, abordando a articulação entre tempo de trabalho e tempo de vida dos professores, e a importância deste profissional para a manutenção e desenvolvimento da ordem econômica brasileira. Apresentou as relações do tempo de trabalho com o tempo de vida, e a necessidade da eficácia do Direito ao Lazer para garantir a fruição deste momento. Analisou a legislação vigente que ampara o trabalhador, expondo o contido na Constituição Federal de 1988 e na Consolidação das Leis do Trabalho, dando destaque para jornada de trabalho e a utilização do tempo livre. Apresentou a forma de ser do trabalho docente na atualidade, as inovações tecnológicas, organização do trabalho e o modo de gestão. Também foram verificadas as condições existenciais de produção do conhecimento e em que medida o conhecimento tornou-se mercadoria comercializável e geradora de lucro. Investigou-se o modo de organização do tempo disponível como tempo de vida e lazer dos professores e os impactos 
das condições objetivas do trabalho docente sobre a saúde e qualidade de vida destes profissionais. Utilizou-se o método dialético e pesquisa bibliográfica, recorrendo ao procedimento dedutivo econômico com meio ambiente ecologicamente equilibrado e saudável para as presentes e as futuras gerações.

Palavras-chave: Professor. Direito ao Lazer. Precarização. Ordem Econômica.

\begin{abstract}
This article investigated the casualization of teaching, focusing on higher education, addressing the relationship between working time and lifetime of the teachers, and the importance of this person for the maintenance and development of the Brazilian economic order. Presented relations of working time to the time of life, and the need for effectiveness of the Right to Leisure to ensure the enjoyment of this moment. Examined the legislation that supports the worker, exposing contained in the Federal Constitution of 1988 and the Consolidation of Labor Laws, giving emphasis on working hours and the use of free time. Showed how to be the teacher's work today, technological innovation, work organization and management mode. Existential conditions of knowledge production were also checked and the extent to which knowledge has become tradeable commodity and generating profit. We investigated the mode of organization of available time as life and leisure time for teachers and the impact of objective conditions of teaching on health and quality of life of these professionals. We used the dialectical method and literature, using the deductive procedure.
\end{abstract}

Keywords: Teacher. Right to Leisure. Precariousness. Economic Order.

\title{
1. Introdução
}

Esta pesquisa, parte da premissa que o trabalho do professor é um "trabalho ideológico", visto que exerce atividade de cuidador e formador do outro e que, pela sua própria natureza material, forma outras pessoas com dedicação e doação pessoal, transmitindo conhecimento e experiência de vida que são elementos sociais no processo produtivo. Entretanto, por outro lado, na medida em que a lógica do capital toma conta da relação de trabalho das profissões, o "trabalho ideológico" tomado de estranhamento desafetiva o homem através da diminuição de seu tempo de vida a tempo de trabalho estranhado e precarizado que atravanca o desenvolvimento humano e econômico.

Verificada a importância do papel do professor como desenvolvedor humano, através da transmissão dos conhecimentos fundamentais para a manutenção e aperfeiçoamento da ordem econômica brasileira, a Constituição Federal de 1934 promulgou, pela primeira vez, a educação 
como um direito de todos, sendo primordial a valorização do professor para a realização deste direito social.

Num primeiro momento, conceitua-se e apresenta as características do lazer, tempo de vida e o tempo de trabalho, apresentando a contribuição dos estudiosos do tema a respeito de elementos de cada momento e a importância da valorização do tempo de vida, para a saúde do profissional e manutenção de sua subjetividade, evitando o estranhamento e resgatando o prazer do exercício da profissão docente.

Posteriormente, apresenta os normativos referentes à proteção do trabalho docente no Brasil e quais as suas finalidades, se intenciona apenas legalizar e regulamentar a organização desta profissão, ou se há a verdadeira defesa e a garantia do trabalho digno e humano destes profissionais. Detalha o Direito ao Lazer do professor, como defensor da garantia de fruição do tempo de vida para que o profissional possa utilizar este tempo livremente, sem obrigação, coação ou interesse meramente econômico.

Em seguida, faz-se análise das principais características da reestruturação produtiva que atingiu diretamente o cotidiano do professor, como a intensificação do trabalho, a premência da flexibilização laboral, a exigência do aumento das produções científicas, a mercantilização do conhecimento e as pesquisas universitárias feitas sob encomendas para atender às demandas do capital.

Os aspectos da reestruturação produtiva ocasionam a perda da subjetividade do professor e a precarização do homem-que-trabalha, verificando-se que, o trabalho e o seu produto não mais pertencem aquele que o criou, gerando um estranhamento tão completo, que o trabalhador é alheio ao processo de criação. À luz do preconizado no artigo 170 da Constituição Federal, de 1988, onde é explícita a valorização do trabalho humano e a essencialidade da dignidade para a manutenção da ordem econômica, constata-se uma antípoda neste cenário, quando observada a rotina de trabalho do professor.

Como embasamento da pesquisa, utilizou-se do método críticodialético, com respaldo em material bibliográfico sobre o tema: livros, legislações, revistas, etc. A exposição do desenvolvimento do artigo darse-á mediante o amparo do procedimento dedutivo. 


\section{O lazer e tempo de vida do professor}

É importante apreender a relação entre tempo de trabalho e tempo de vida do professor e o modo de organização da estrutura do tempo disponível, buscando entender como este é usufruído. Para István Mészáros, o homem-que-trabalha nas condições do sociometabolismo do capital tem sua subjetividade e personalidade afetada pelo movimento de redução do tempo de trabalho necessário e ampliação do tempo de trabalho excedente apropriado pelas necessidades da acumulação de valor. Diz Mészáros:

O trabalho obtém concessões ao preço de ser forçado a constantemente reduzir o volume de trabalho necessário requerido para assegurar a continuidade do processo de reprodução capitalista. Todavia, não conquista o poder de tornar aceitável a legitimidade (e a necessidade) de organizar a produção de acordo com o princípio do tempo disponível: a longo prazo, única salvaguarda viável contra a sujeição à extrema penúria e à indignidade do desemprego em massa. E o capital, por outro lado, obtém êxito em transformar os ganhos do trabalho em sua própria auto expansão lucrativa e dinâmica ao elevar incansavelmente a produtividade do trabalho; entretanto, não encontra solução adequada para crescentes complicações e perigosas implicações do desemprego crônico e da superprodução concomitante, que prenunciam seu colapso final como modo socialmente viável de reprodução produtiva (2002, p. 667.)

De acordo com o autor, o tempo disponível é a única salvação contra a indignidade, visto que é o tempo em que o trabalhador é livre para criar, contemplar, estudar, passear, ouvir música etc; e a diminuição do tempo de trabalho é alternativa no combate ao desemprego.

Alguns pesquisadores, nacional e internacional, utilizaram-se do termo lazer, quando discutem o tempo de vida, este conceito será o adotado na pesquisa. Entretanto, tempo de vida não se reduz a lazer. Dentre as definições de lazer, a mais adotada pelos estudiosos é a dada pelo sociólogo francês Joffre Dumazedier:

O lazer é um conjunto de ocupações às quais o indivíduo pode entregarse de livre vontade, seja para repousar, seja para divertir-se, recrear-se e 
entreter-se ou, ainda, para desenvolver sua informação ou formação desinteressada, sua participação social voluntária ou sua livre capacidade criadora após livrar-se ou desembaraçar-se das obrigações profissionais, familiares e sociais (1973, p. 34).

0 autor relaciona lazer à satisfação de algumas necessidades humanas como o repouso, a diversão, a recreação, a distração e o desenvolvimento intelectual. Para Dumazedier (1973, p. 32) o lazer é uma atividade ou inatividade voluntária, onde o homem se sente liberto de qualquer grilhão. Para o sociólogo, este é o futuro substituto do trabalho alienado e tende a ser o tempo de uma autoformação permanente e voluntária. Este dispõe de três categorias, que são as principais funções do lazer: descanso; divertimento, recreação e entretenimento e desenvolvimento físico e mental. Por outro lado, Marcellino define o lazer:

[...] como a cultura - compreendida no seu sentido mais amplo - vivenciada (praticada ou fruída) no 'tempo disponível'. O importante, como traço definidor, é o caráter 'desinteressado' dessa vivência. Não se busca, pelo menos fundamentalmente, outra recompensa além da satisfação provocada pela situação. A 'disponibilidade de tempo' significa possibilidade de opção pela atividade prática ou contemplativa (1995, p. 31).

O autor dá ênfase à voluntariedade da ação ou omissão realizada pelo homem, pois o tempo disponível como tempo de vida deve ter caráter voluntário e livre de obrigações ou coações externas: o que se busca é a satisfação pessoal.

Para Renato Requixa (1980, p. 35), lazer é uma ocupação livre e seus valores devem propiciar condições de recuperação psicossomática e desenvolvimento pessoal/social. É um momento de ociosidade e contemplação.

Na mesma linha de argumentação, Ethel Medeiros considera o lazer como:

[...] espaço de tempo não comprometido do qual podemos dispor livremente, porque já cumprimos nossas obrigações de trabalho e de vida, destacando como funções do lazer para o homem contemporâneo, o repouso, a diversão e o desenvolvimento pessoal (1971, p. 30-31). 
Para Requixa e Medeiros, o tempo de vida como lazer está relacionado ao não trabalho e desobrigação familiar, política e social, ou seja, no momento de lazer o indivíduo pode ser ele mesmo, fazendo ou não fazendo algo.

Requixa e Medeiros tratam do lazer e não do conceito de tempo de vida, tendo em vista que reduzir este tempo ao lazer é um equívoco, pois reduz tempo disponível não apenas da desobrigação de trabalho, mas também da desobrigação de vida familiar, política e social, excluindo, deste modo, do tempo de vida como tempo disponível, a fruição de relações sociais, familiares e políticas. 0 Direito ao Lazer é a alternativa legal para se garantir o tempo de vida do professor, sendo indispensável que o mesmo seja sistematizado juridicamente e acionado por estes profissionais e seus sindicatos.

Portanto, como se salienta o tempo de vida não se reduziria a lazer visto como sinônimo de não fazer, limitado ao direito de opção a não fazer algo. Na verdade, o tempo de vida não inclui apenas repouso, diversão, namoro, práticas esportivas, entretenimento ou contemplações capazes de satisfazer as pessoas no plano individual, mas principalmente atividades sociais, políticas e coletivas, ou ainda, encontrar amigos e familiares, e até mesmo o trabalho comunitário, dentre outras atividades de interação social. 0 tempo disponível como tempo de vida implica fruição da vida humano-genérica, isto é, vida social plena de relações humanas interpessoais. No entanto, tanto o tempo de vida como o lazer são momentos que devem ser garantidos pela legislação, através do Direito ao Lazer.

Não se deve confundir também tempo de vida com tempo de consumo. Conforme leciona Sarah Bacal (2003, p. 87), tende a converter o tempo disponível em tempo de consumo como objetivo capaz de preencher suas exigências de gratificação, sua vida. Por exemplo, os publicitários não propõem lazeres que não exijam poder de compra, para ela:

$\mathrm{Na}$ medida em que sob o capitalismo fordista o consumo fetichizado ocupou o tempo de vida e lazer, criaram-se as condições sociometabólicas para que o tempo de vida esvaziado de conteúdo se tornasse tempo de trabalho estranhado e fetichizado nas condições do capitalismo toyotista. Portanto, antes de ser reduzida a trabalho abstrato fictício, a vida 
foi esvaziada de conteúdo efetivamente humano pelo consumo fetichista (2013, p. 125).

De acordo com Alves (2013), o consumo fetichizado tomou conta da sociedade atual. 0 consumo praticado no tempo de lazer colabora com o estranhamento e a alienação do homem visto que este consome o que está condicionado a consumir, desta forma não se encontra consigo mesmo e com sua subjetividade. No momento em que o homem é condicionado em suas ações, mesmo nos momentos de não trabalho, este perde sua humanidade e sua dignidade, visto que é um estranho para si mesmo.

Após a análise do tempo de vida, ou tempo de lazer, concluindo ser este um momento de fruição da liberdade do trabalhador, dentre eles o professor, faz-se importante apresentar legislação vigente, referente à jornada de trabalho e a rotina de vida deste profissional, para constatar se lhe é garantido o Direito ao Lazer.

\section{As garantias do direito ao lazer do professor no Brasil}

A Constituição Federal de 1934 (BRASIL, 2014), com destaque para os artigos 5ㅇ, 149 e 150 a 157 trouxe pela primeira vez a educação como um direito de todos, em que o aprendizado escolar está focado em conhecimentos científicos e comportamentais, alicerçado em valores morais.

Desde a promulgação desse documento, é enfatisado juridicamente o papel do professor para garantir o direito social à educação a todos os cidadãos. Conforme previsto no artigo 6음 da Constituição Federal de 1988 (BRASIL, 2003a), a educação é um direito social, e julga ser um direito de todos os cidadãos brasileiros.

Hodiernamente, na Constituição de 1988, bem como na Lei de Diretrizes e Bases da Educação (Lei no 9.394, de 20 de dezembro de 1996), foi exposto nos seus textos princípios e normas para a valorização dos professores e garantia à dignidade deste profissional. Traz à baila que, embora se note o avanço legal nos aspectos de proteção e de valorização do professor, este amparo não tem sido suficiente para evitar a sua precarização, também em decorrência da falta de fruição do Direito ao Lazer. 
Na Magna Carta, estão elencados no artigo 170, os princípios fundantes da ordem econômica brasileira que, dentre eles, estão à valorização do trabalho humano, a livre iniciativa e a garantia de existência digna para todos, conforme os ditames da justiça social. Obviamente, ao professor deve ser garantido o princípio da dignidade da pessoa humana, devendo o mesmo ser tratado como um fim em si mesmo, e não um meio, ou uma mercadoria.

Para a concretização dos Direitos Sociais, com foco no direito à educação, apreende-se a importância da concretização de políticas públicas na busca e incentivo a realização de prerrogativas individuais e coletivas, designado a diminuir as desigualdades sociais existentes e a garantir uma existência humana digna, no entanto, nota-se que em alguns aspectos a intervenção estatal produz resultado inverso à defesa dos Direitos Sociais.

0 Estado tem papel fundamental na realização do direito à educação e na valorização do professor, no entanto às vezes a intervenção estatal prejudica a formação e criação do professor, como no âmbito político, esta influência deve ser exercida avaliando os procedimentos a serem adotados e consequências, para que atinja o seu objetivo que é a efetividade da dignidade do profissional e melhoria na educação dos cidadãos brasileiros, para que se formem bons profissionais e homens críticos da realidade da sociedade em que está inserido.

No âmbito político, persiste a racionalidade mercantil na esfera estatal (intervenção do Estado no mercado), que, na esfera da educação superior, apresenta-se como Estado gestor estabelecendo instrumentos jurídicos para a conformação da identidade universitária e avaliar, regular e controlar a liberdade acadêmica, primordial às atividades e ao desenvolvimento do professor-pesquisador das universidades estatais públicas. Esta intervenção é o bastante para comprometer a harmonia psíquica e psicossomática deste profissional, gerando estresse e às doenças psicossomáticas daí decorrentes (SILVA JÚNIOR, SGUISSARDI, 2009)

O direito à educação está exposto na Constituição Federal de 1988 (BRASIL, 2003a), artigos 6ำ e 205 a 214, onde prescreve que o Estado, a família e a sociedade devem atuar para garantir este direito e o pleno desenvolvimento da pessoa, preparando-a para o exercício da cidadania e qualificando-a para o trabalho (artigo 205), ratificando a importância 
do professor na formação profissional e, consequêntemente, na manutenção e aperfeiçoamento da ordem econômica do país.

É indiscutível que o professor exerce função essencial quanto à impulsão da educação promotora de desenvolvimento econômico, social e individual, e por isso, este carece de um tempo de vida que deve ser garantido juridicamente. A Magna Carta (BRASIL, 2003a) dispõe no artigo 206, inciso $\mathrm{V}$, como um dos princípios que devem reger as atividades de ensino, a valorização dos diversos profissionais da área da educação, sendo expressamente assegurada a importância do ser humano na qualidade do ensino.

A Consolidação das Leis do Trabalho, Decreto-lei ${ }^{\circ} 5.452$, de $1^{\circ}$ de maio de 1943, no título das normas especiais de tutela do trabalho, prescreve regras específicas aos professores, conforme descreve o artigo 317 ao artigo 324 .

Aponta-se na Consolidação das Leis do Trabalho (BRASIL, 2003b), a descrição sobre a carga horária a que estão submetidos os professores, conforme descrito no artigo 318, este não poderá ministrar mais de quatro aulas consecutivas, nem seis intercaladas num mesmo estabelecimento, o que exceder esse limite será considerado como jornada extra, que deve ter remuneração, no mínimo, em $50 \%$ (cinqüenta por cento) à normal, por força do disposto no artigo 7ํㅡ, item XVI da Constituição Federal (BRASIL, 2003a), bem como atendendo o que dispõe o artigo 321 da Consolidação das Leis do Trabalho (BRASIL, 2003b).

É possível que o professor trabalhe em mais de um estabelecimento de ensino, o que acontece, normalmente, visto a necessidade de complemento de seus rendimentos. A atividade do professor não está limitada a ministrar aulas, sua jornada de trabalho é muito mais extensa:

[...] o professor tem de prepará-las em casa, o que demanda tempo, corrigir provas e trabalhos, atividades que a lei não determina pagamento ao professor. Atividades extraclasse, prestadas na casa do professor, como de correção de provas e trabalhos, preparação de aulas, não são consideradas horas extras, até porque não há fiscalização do empregador nesse sentido e a atividade é externa. Daí por que nas normas coletivas se colocar outro pagamento chamado hora-atividade, que tem por fim remunerar a preparação de aulas do professor (MARTINS, 2009). 
O que se constata é que a atividade do professor não está sujeita apenas a ministrar as aulas, pois o profissional tem de prepará-las em casa, corrigir provas e trabalhos, consumindo o seu tempo e não recebendo remuneração extra, pois este tempo não é considerado tempo de trabalho. Por isso, para suprir essa lacuna, as categorias patronal e profissional têm buscado soluções nas convenções coletivas e sentenças normativas, que apresentam um pagamento complementar. Esse recurso tem por fim remunerar a preparação de aulas do professor

Conforme descrito no artigo 320 da Consolidação das Leis do Trabalho, a remuneração dos professores será fixada pelo número de aulas semanais, detalhando:

Art. 320 - A remuneração dos professores será fixada pelo número de aulas semanais, na conformidade dos horários.

§ 1으 - O pagamento far-se-á mensalmente, considerando-se para este efeito cada mês constituído de quatro semanas e meia.

$\S 2$ o - Vencido cada mês, será descontada, na remuneração dos professores, a importância correspondente ao número de aulas a que tiverem faltado.

§ 3o - Não serão descontadas, no decurso de 9 (nove) dias, as faltas verificadas por motivo de gala ou de luto em conseqüência de falecimento do cônjuge, do pai ou mãe, ou de filho. (BRASIL, 2003b).

Referente ao adicional noturno, este será remunerado com a redução do horário da aula. No entanto, há entendimento diverso, como por exemplo, o de Sergio Pinto Martins, no qual defende que a redução da hora noturna, como previsto na Consolidação das Leis do Trabalho, embora seja mais benéfico ao professor, não é o mesmo que o pagamento de adicional noturno (MARTINS, 2009).

Em relação às férias, preleciona o artigo 322 da Consolidação das Leis do Trabalho (BRASIL, 2003b) que: "No período de exames e no de férias escolares, é assegurado aos professores o pagamento, na mesma periodicidade contratual, da remuneração correspondente por eles percebida, na conformidade dos horários, durante o período de aulas." E, no 2o parágrafo do mesmo artigo: "No período de férias, não se poderá exigir dos professores outro serviço senão o relacionado com a realização de exames". 
Desta forma, obriga-se separar as férias escolares ou recesso escolar, que ocorrem em dois períodos (julho e de dezembro a janeiro de cada ano) com as férias individuais do professor. Essas podem ser fixadas tanto em julho como de dezembro a janeiro, ou seja, em um mês em que não existam aulas escolares.

Feita a apresentação da legislação pertinente à jornada de trabalho do professor, que possibilitaria a prática do Direito ao Lazer, onde poderia exercer atividades livres como contemplar, ler sem compromisso, viajar, ouvir música, etc. Parte-se para o estudo da prática laboral do docente, no momento vigente, e em que momento este pratica o tempo de vida.

\section{A intensificação do trabalho docente}

Nas condições do capitalismo gobal, presencia-se o aumento da intensidade do trabalho. De acordo com Sadi Dal Rosso (2008, p. 20), a intensidade tem a ver com a maneira como é realizado o ato de trabalhar, este se refere ao grau de dispêndio de energias realizado pelos trabalhadores na atividade concreta. Esta compreensão também pressupõe que a atenção esteja concentrada sobre a pessoa do trabalhador, sobre o coletivo dos trabalhadores, e não sobre outros componentes do processo de trabalho que têm capacidade de alterar os resultados, tais como as condições tecnológicas. Neste sentido, a intensificação do trabalho do professor:

Conduz à redução do tempo para descanso na jornada de trabalho; implica a falta de tempo para atualização em alguns campos e requalificação em certas habilidades necessárias; implica uma sensação crônica e persistente de sobrecarga de trabalho que sempre parece estar aumentando, mais e mais tem para ser feito e menos tempo existe para fazer o que deve ser feito. Isso reduz áreas de decisão pessoal, inibe envolvimento e controle sobre planejamento de longo prazo, aumentando a dependência a materiais externos e a técnicos especialistas também externos ao trabalho, o que provoca um aumento da separação entre concepção e execução, entre planejamento e desenvolvimento; conduz à redução na qualidade do tempo, pois para se "ganhar" tempo somente o "essencial" é realizado. Isso aumenta o isolamento, reduzindo as chances de interação (já que a participação motiva comportamento crítico) e limi- 
tando as possibilidades de reflexão conjunta. Habilidades coletivas de trabalho são perdidas ou reduzidas enquanto habilidades de gerência são incrementadas; produz uma imposição e incremento diversificado de especialistas para dar cobertura a deficiências pessoais; introduz soluções técnicas simplificadas (tecnologias) para as mudanças curriculares a fim de compensar o reduzido tempo de preparo (planejamento); frequentemente os processos de intensificação são mal interpretados como sendo uma forma de profissionalização e muitas vezes é voluntariamente apoiada e confundida como profissionalismo (HYPOLITO, 2009).

Nos anos 1990, as mudanças no sistema educacional trouxeram novas metas para a academia, dentre elas, a promoção da educação para o equilíbrio social e formação de indivíduos para o mercado de trabalho. A reestruturação produtiva e as reformas no mundo do trabalho, ascensão do neoliberalismo e a adequação da função estatal apresentaram papel expressivo no processo de mundialização da economia, tendo alcance importante no campo da educação (SANT'ANA, 2010). Dessa forma, faz-se necessário posicionar o tema da precarização do exercício da função docente nas mudanças ocorridas nos últimos trinta anos no Brasil. Relacionando este assunto aos docentes, coloca-se Bosi:

[...] a pressão exercida para aumentar a quantidade de trabalho dentro da jornada de 40 horas tem se concretizado, principalmente, alicerçada na idéia de que os docentes devem ser "mais produtivos", correspondendo à "produção", a quantidade de "produtos" relacionados ao mercado (aulas, orientações, publicações, projetos, patentes etc.) expelidos pelo docente. Por um lado, evidencia esse processo o direcionamento empresarial da ciência, tecnologia, pesquisa e desenvolvimento, presente nos editais dos órgãos e fomento à produção científica. Cada vez mais, a CNPq e as fundações estaduais de apoio à pesquisa tem convertido seus recursos para pesquisas e estudos que aparelhem e potencializem a capacidade de reprodução do capital, desenvolvendo uma razão instrumental que pode ser facilmente verificada no caráter dos editais divulgados. 0 perfil de pesquisa que escorre caudalosamente desses editais termina por ditar o padrão para a produção acadêmica em geral. Uma das consequências desse processo é que a qualidade da produção acadêmica passa então a ser mensurada pela quantidade da própria produ- 
ção e por valores monetários que o docente consegue agregar ao seu salário e à própria instituição (BOSI, 2007, p. 1513).

Portanto, o modelo produtivista das novas formas de gestão toyotista gera a perda da autonomia intelectual e do controle sobre o processo de trabalho configurando na subsunção do trabalho intelectual à lógica do capital, visto que os professores que se colocam contra este sistema são vistos como "improdutivos". Silva Jr e Silva (2013) tratam deste assunto e informam que: "Sofrimento, mal-estar, estranhamento: eis o que resultou da incorporação da teleologia com valores instituídos pela CAPES". (SILVA JR; SILVA, 2013, p. 225), os autores completam declarando que o trabalho intensificado limita a fruição do tempo disponível, da vida familiar, atingindo a saúde do professor.

Na sociedade contemporânea, a intensidade do trabalho está voltada para os resultados que devem ser qualitativa e quantitativamente superior, razão pela qual se exige um consumo maior de energias do trabalhador. Esta intensificação é observada quando há maior gasto de energias do trabalhador sejam elas físicas ou psíquicas (trabalho imaterial) (DAL ROSSO, 2008, p. 21).

A intensificação do trabalho e a diminuição do tempo disponível como tempo de vida são elementos da precarização existencial que causa estresse ideológico gerado pela precarização do homem como ser humano-genérico, a precarização existencial refere-se à degradação das condições de existência do trabalho vivo no território das metrópoles e nos espaços públicos de desenvolvimento humano (inclusive Universidades Públicas), isto é, as condições da reprodução social como circulação, territorialidade, consumo e lazer. (ALVES, 2013).

A precarização existencial do professor, ocasionada pela diminuição do tempo de vida e a não efetividade do Direito ao Lazer, fere o que está prescrito no artigo 170 da Constituição Federal, visto que quando ocorre a perda ou restrição deste tempo de vida, há como resultado a ausência da sua dignidade e humanidade, pois se torna, além de um escravo do trabalho, uma mercadoria, visto que não possui liberdade para pensar e criar, preso em grilhoes de tempo e espaço determinados, produzindo de acordo com o que lhe é encomendado.

Como exemplo da intensificação do trabalho docente, tem-se o caso da Unesp - Universidade Estadual Paulista, de acordo com os anuá- 
rios estatísticos da Universidade (2014), entre os anos de 2002 e 2013, houve um aumento de 40,93\% no número de alunos de graduação, que passou de 25.738 para 36.264; e um aumento de 39,3 \% no número de alunos de pós-graduação (mestrado e doutorado), que passou de 9.204 para 12.818. Entretanto, no mesmo período, o número de professores contratados elevou apenas $16,5 \%$, passando de 3.201 para 3.730 , comprovando a tendência à intensificação do trabalho docente.

Na medida em que se desenvolve a grande indústria, a criação de riqueza real vem a depender menos do tempo de trabalho e da quantidade de trabalho empregado do que da potência/intensidade dos agentes que vêm colocados em ação durante o tempo de trabalho. 0 capital, quando dissemina o trabalho estranhado corrói os atributos da pessoa humana e distância os três atributos fundantes e fundamentais da humanidade do ser: individualidade; subjetividade e alteridade (ALVES, 2013, p. 117).

Marx (1967), ao estudar o processo de mecanização da produção, desloca seu ideal de emancipação humana do campo do trabalho para o do tempo disponível ou tempo de vida - que se ampliaria progressivamente com o desenvolvimento das forças produtivas, sobretudo com o progresso técnico dos meios de produção, enfim, da maquinaria automática, reduzindo o tempo de cada indivíduo dedicado ao trabalho necessário e excedente (enfim, a jornada de trabalho toda).

Karl Marx (1967) acreditava que em toda sociedade onde habitassem homens e mulheres, deveria haver possibilidade de desenvolvimento de suas habilidades e aperfeiçoamento, não apenas como ferramentas de trabalho para produção de mercadorias, mas também como pessoas capazes de opinar e desenvolver sua intelectualidade, para isso é primordial o tempo disponível. Para o autor, o trabalho é uma das causas de toda degeneração intelectual, de toda deformação orgânica, da depreciação da arte, do belo e da supervalorização do vulgar e do massificado.

Em consonância ao exposto por Marx, Alves (2013) destaca a "precarização do homem-que-trabalha" - homem como ser humanogenérico -, por conta da exploração e condições salariais. Esta precarização ocorre no plano da subjetividade humana, ocasionando desequilíbrios metabólicos das individualidades pessoais e, principalmente, gerando a redução do tempo disponível a tempo de trabalho. 
Russell em sua obra "O Elogio ao Ócio", retrata a repulsa à supervalorização do trabalho e a crença de que este seja um meio de felicidade:

[...] eu acho que se trabalha demais no mundo de hoje, que a crenças nas virtudes do trabalho produz males sem conta e que nos modernos países industriais é preciso lutar por algo totalmente diferente do que sempre se apregoou.

Quero dizer, com toda a sinceridade, que muitos malefícios estão sendo causados no mundo moderno pela crença na virtude do trabalho, e pela convicção de que o caminho da felicidade e da prosperidade está na redução organizada do trabalho (2002, p. 23-25).

Para Russel a felicidade não se encontra no tempo de trabalho, ela está presente no tempo de vida ou tempo de existência, no tempo em que o homem se realiza e se liberta do estranhamento originado no ambiente de produção do capital e é neste tempo em que o homem vive com dignidade humana.

O cenário do capitalismo global do século XXI apresenta-se contraditório, exigindo uma análise crítica, visto que se o trabalho ainda é central para a criação do valor - reiterando seu sentido de perenidade estampa, em patamares assustadores, seu traço de superfluidade, da qual são exemplos os precarizados, flexibilizados e temporários, características pertinentes ao trabalho docente além do grande exército (de reserva) de desempregados e desempregadas existentes no mercado mundial.

Na era da mundialização do capital, verifica-se uma fase de globalização das lutas sociais do trabalho (como exemplo, a população indo às ruas e manifestando-se exigindo direitos e melhorias), nelas incluídas as massas de desempregados que se ampliam em escala global. Sobre a mundialização, diz-nos François Chesnais (1996, p. 24):

A palavra "mundial" permite introduzir, com muito mais força do que o termo "global", a idéia de que, se a economia se mundializou seria importante construir depressa instituições políticas mundiais capazes de dominar o seu movimento. Ora, isso é o que as forças que atualmente regem o destino do mundo não querem de jeito nenhum. 
Na verdade, a crise estrutural do capital, caracterizada por dois processos críticos fundamentais, o de formação de valor e o de (de)formação humano-social (ALVES, 2012) vem promovendo a precarização do trabalho vivo tanto como mercadoria (precarização do trabalho) quanto como ser humano-genérico (precarização do homem-quetrabalha, precarização existencial). 0 novo metabolismo social do trabalho caracteriza-se pelas novas formas de consumo (da força de trabalho como mercadoria) e pelos novos modos de (des) constituição (do ser genérico do homem), alterando a relação "tempo de vida"/"tempo de trabalho" e o espectro de sociabilidade e de auto-referência pessoal (elementos do processo de formação do sujeito humano-genérico).

Uma nova morfologia social do trabalho, resultante de tais processos sócio-históricos, emerge com dinâmicas psicossociais que implicam: (01) na dessubjetivação de classe; (02) na captura da subjetividade do homem-que-trabalha; e (03) na redução do trabalho vivo à força de trabalho como mercadoria, gerando, como consequência, uma crise da subjetividade e do trabalho vivo, percebida em três importantes dimensões: (a) crise da vida pessoal (crise do homem com seu espaço de vida); (b) crise da sociabilidade (crise do homem com outros homens); e (c) crise de auto-referência (crise do homem com ele mesmo). (ALVES, 2012)

Devido à natureza do trabalho docente como trabalho ideológico muitas vezes tempo de vida e tempo de trabalho não possuem distinções claras entre ambos, determinado em função dos ciclos da vida e do trabalho.

Para Marx, a falta de tempo disponível do professor esta intrinsecamente ligada ao seu processo de proletarização (MARX, 1967, p. 88171), consistindo na mercantilização do corpo e da mente. Esta é uma nova dimensão da precarização do trabalho que não se reduz a precarização salarial, mas envolve a precarização existencial.

Um dos elementos cruciais da precarização laboral dos docentes com impacto nas condições da produção do conhecimento científico ocorre por meio da "invasividade" do tempo de vida pelo tempo de trabalho ou ainda, pela "captura" da subjetividade do professor pelos requerimentos do novo modo de gestão do trabalho docente nas universidades públicas. 
Depreende-se que a redução da jornada de trabalho não torna imediatamente o tempo liberado pelo desenvolvimento das forças produtivas em tempo dedicado a este exercício de liberdade e autorrealização, decorrente da captura da subjetividade do trabalhador. Há risco de que este seja degradado pela cultura de massa e entretenimento, a indústria cultural, visando tão somente às oportunidades econômicas do lucro. Portanto, embora se considere como alternativa, a diminuição do tempo de trabalho não garante a prática do Direito ao Lazer.

Conforme apontado, a intensificação do trabalho docente, e extensas jornadas de trabalho dentro e principalmente fora das salas de aula, conjugado com outros fatores, como a pressão por produções científicas, encomendas de pesquisa, etc, resulta na precarização do trabalho docente, tema que coaduma a este artigo.

\section{Precarização do trabalho docente}

Como visto, com a intensificação do trabalho docente nas universidades, há a precarização que naturaliza ocorrências como: substituição de colegas para cobrir a falta de contratação de professores; correções de provas e trabalhos, planejamento de aulas, atividades realizadas durante o tempo disponível do docente, nos finais de semana ou mesmo em trânsito, dentro do ônibus. A professora Vera Navarro alerta-nos sobre a flexibilização do trabalho, como mais um processo de intensificação:

O trabalhador ideal do ponto de vista do capital deve ser polivalente e flexível e, além disso, deve se dispor a levar o trabalho para ser realizado em sua própria casa. Tal trabalho flexível, segundo a ideologia dominante, possibilita ao trabalhador mais liberdade para administrar seu tempo, para moldar sua vida (NAVARRO, 2006, p. 72).

Em consonância ao exposto pela autora, constata-se que não está clara a delimitação do tempo de trabalho e tempo de vida do profissional docente. Este trabalha enquanto vive e vive enquanto trabalha.

Hoje, no período em que o trabalho docente, é qualitativamente generalizado e tendencialmente hegemônico, o intelectual se encontra por inteiro no interior do processo produtivo. Quer a atividade do inte- 
lectual se exercite na formação ou na comunicação, quer nos projetos industriais ou nas técnicas das relações políticas, em todos os casos, o intelectual não pode mais ser separado da máquina produtiva. 0 intelectual está aqui em completa adequação aos objetivos da libertação sendo o novo sujeito, poder constituinte não sabe do que, potência do comunismo de base consumista (NEGRI; LAZZARATO, 2001, p. 30).

A particularidade da mercadoria produzida pelo trabalho imaterial na forma de trabalho ideológico está no fato de que ela não se destrói no ato do consumo, mas alarga, transforma, cria o ambiente ideológico e cultural do consumidor (exemplo típico do fetichismo da mercadoria). A mercadoria não reproduz a capacidade física da força de trabalho, mas transforma o seu utilizador, até porque o trabalho imaterial é o que produz conhecimento, no entanto atualmente o mesmo é confundido com uma mercadoria.

É cada vez mais evidente a consciência de que as atividades cerebrais predominam em relação às manuais, que as atividades virtuais prevalecem sobre as tangíveis. Seja no horário de trabalho, seja durante o tempo disponível, agem-se mais com a cabeça, em vez de usar a força física. Nesta linha de pensamento, comenta Karl Marx:

Trata-se agora de desenvolver livremente as individualidades, e não de reduzir o tempo de trabalho necessário, tendo em vista criar trabalho excedente; a redução do trabalho necessário da sociedade a um mínimo passa a corresponder à formação artística, científica etc., dos individuos graças ao tempo que se tornou livre e aos meios criados para todos (1973, p. 229).

Este tempo de vida das individualidades, conquistado pelo tempo liberado através dos progressos das forças produtivas do trabalho social, é o ideal emancipatório que surge neste texto. 0 tempo de vida destinado ao desenvolvimento integral e livre dos indivíduos somente é criado através do aumento da produtividade do trabalho que objetiva reduzir o tempo de trabalho necessário em relação ao tempo de trabalho excedente, produtor de mais-valia, e desta forma reduzir a jornada toda de trabalho; liberar o tempo para que este tempo disponível possa se converter em arte, ciência, enfim, conhecimento e criação. 
Muitas vezes a redução na jornada de trabalho, possível alternativa a precarização do trabalho docente, resulta na redução salarial do trabalhador e este está condicionado a acumular e a consumir.

Também, a cultura do desempenho ao contrário do caráter humanista e formador da educação, leva os sujeitos a ações competitivas, individualistas e alienantes. Essa cultura nega o espaço escolar universitário como formador. Sua natureza apresenta-se em harmonia às características neoliberais produtivista, que acompanha uma visão tecnocrática e gerencial do trabalho (SANTOS, 2004). Através desta cultura, há intensificação do trabalho como forma de comportamento condicionado e argumento de sua própria sobrevivência.

Para Marx (1967, p. 156), o trabalho à sombra de relação de dominação impõe-se ao homem como simples meio de existência, isto é, como uma atividade que tem como único sentido o de garantir a sobrevivência física. Mas, segundo o mesmo autor, a atividade vital humana é tanto a responsável ou a base para prover as condições materiais de existência, quanto engendradora da vida genérica do homem. Isto quer dizer que, além de produzir os meios necessários para a existência física, a atividade vital humana produz, ao mesmo tempo, a humanização ou autocriação do gênero humano através do processo de objetivação.

No trabalho alienado, "a vida mesma aparece só como meio de vida" (Marx 1967, p. 156, grifo do autor), sendo entendido, assim, como meio de existência, como uma aparente atividade, como exterior ao trabalhador e não como ato que desenvolve novas capacidades e cria novas necessidades, não como essência humana no sentido da realização das potencialidades alcançadas pelo gênero humano.

Considerando este referencial, o trabalho do professor será alienado quando seu sentido não corresponder ao significado dado pelo conteúdo efetivo dessa atividade prevista socialmente, isto é, quando o sentido pessoal do trabalho separar-se de sua significação.

Se o sentido do trabalho docente, atribuído pelo professor que o realiza, for apenas o de garantir sua sobrevivência trabalhando só pelo salário e sem ter consciência de sua participação na produção das objetivações na perspectiva da genericidade, haverá a cisão com o significado fixado socialmente. Esse significado é entendido como função mediadora entre o aluno e os instrumentos culturais que serão apropriados, visando ampliar e sistematizar a compreensão da realidade, e possibili- 
tar objetivações em esferas não cotidianas. Nesse caso, o trabalho alienado do docente pode descaracterizar a prática educativa.

A perda do significado traz à baila o estranhamento que, para Marx (1967), ocorre quando o trabalhador não se reconhece mais em seu trabalho; acontece quando a atividade laboral deixa de ter um caráter criativo e passa a servir ao capital, de acordo com o autor:

[...] o estranhamento não se mostra somente no resultado, mas também, e, principalmente, no ato da produção, dentro da própria atividade produtiva. Como poderia o trabalhador defrontar-se alheio ao produto na sua atividade se no ato mesmo da produção ele não se estranhasse a si mesmo? 0 produto é, sim, somente o resumo da atividade, da produção. Se, portanto, o produto do trabalho é a exteriorização, então a produção mesma tem de ser a exteriorização ativa, a exteriorização da atividade, a atividade da exteriorização. No estranhamento do objeto do trabalho resume-se somente o estranhamento, a exteriorização da atividade do trabalho mesmo. (MARX, 1967, p. 82, grifos do autor)

De encontro com o trabalho estranhado, Marx define a exteriorização do trabalho, prática comum no modo de produção capitalista, que afeta a vida do professor:

Em que consiste, então, a exteriorização do trabalho?

Primeiro, que o trabalho é externo ao trabalhador, isso é, não pertence ao seu ser, que ele não se afirma, portanto, em seu trabalho, mas nega-se nele, que não se sente bem, mas infeliz, que não se desenvolve nenhuma energia física e espiritual livre, mas mortifica sua physis e arruína o seu espírito. 0 trabalhador só se sente, por consequinte e em primeiro lugar, junto a si (quando) fora do trabalho e fora de si (quando) no trabalho. Está em casa quando não trabalha e, quando trabalha, não está em casa. O seu trabalho não é, portanto, voluntário, mas forçado, trabalho obrigatório. 0 trabalho não é, por isso, a satisfação de uma carência, mas somente um meio para satisfazer necessidades fora dele. Sua estranheza evidencia-se aqui (de forma) tão pura que, tão logo inexista coerção física ou outra qualquer, foge-se do trabalho como de uma peste. 0 trabalho externo, o trabalho no qual o homem se exterioriza, é o trabalho de auto ssacrifício, de mortificação. Finalmente, a externalidade do trabalho apa- 
rece para o trabalhador como se (o trabalhado) não fosse seu próprio, mas de um outro, como se (o trabalho) não lhe pertencesse, como se no trabalho não pertencesse a si mesmo, mas a um outro. (MARX, 1967, p. 82-83)

O que se verifica, no caso do trabalho docente, é que no final do processo de trabalho, ocorre a materialização de um produto que é estranho ao trabalhador, sendo propriedade do capitalista, visto que no capitalismo, nem o produto nem o processo de trabalho pertencem ao profissional. Além disso, verificam atribuições alheias à educação escolar que colaboram com a precarização e estranhamento da profissão docente:

A escola passa a assumir novas funções que trazem diversificadas exigências, como por exemplo, suprir necessidades de lazer e cultura da região onde se situa, realizar ações de educação em saúde, dentre outras, desdobrando-se para construir propostas como "escola aberta" aos finais de semana, realização de projetos em parceria com iniciativa privada e comunidade local, dentre outros. Esse cenário traz um sentimento de desprofissionalização e de perda de identidade profissional ao professor, além de representar a desqualificação do seu trabalho (SANT'ANA, 2010).

A intensificação e flexibilização do trabalho docente põe nítidas as condições objetivas para o desenvolvimento do trabalho, que ao invés de colaborar com a emancipação do homem pela apreensão da cultura produzida ontologiamente através do trabalho, terminam por atrelar-se a negação da essência humana em decorrência de atitudes orientadas por práticas que dão preferência a ações individualizadas e competitivas entre os profissionais.

Quando se usurpa a essência humana do trabalhador, lhe é tirado qualquer resquício de dignidade e liberdade, sendo que o mesmo vive em função de um trabalho que lhe é estranho e desagradável. No caso do professor, constata-se que macula o que preconiza o artigo 170 da Constituição Federal, visto que a dignidade e a humanidade são princí- 
pios preteridos, para que se concretizem os objetivos da economia de mercado.

\section{Conclusão}

0 artigo 170, caput, da Magna Carta declara que são princípios fundantes da ordem econômica brasileira a valorização do trabalho humano e a dignidade, estes são extendidos ao professor. 0 professor possui uma das funções mais sofisticadas da sociedade brasileira que é a de transmissão de conhecimentos, experiências e o despertar crítico; formando cidadãos pensantes e criativos que sejam capazes de mudar a realidade (para melhor) e profissionais qualificados.

O exercício do Direito ao Lazer, para promoção do tempo de vida do docente, é garantido pela Constituição Federal e Consolidação das Leis do Trabalho, que dispõe sobre o tempo de férias, hora-aula, descanso semanal remunerado, etc; no entanto, constatou-se que a jornada de trabalho do professor vai muito além da presença em sala de aula. As atividades como a preparação de aulas e provas, correção de provas, pesquisas, aplicação de questionários, cursos de atualização e aperfeiçoamento não são previstos na legislação, sendo remunerados apenas através de negociações coletivas.

A flexibilização e intensificação do trabalho docente dificulta a delimitação do tempo de vida e do tempo de trabalho, ocasionando a perda de subjetividade e liberdade deste profissional, que muitas vezes não pratica o Direito ao Lazer para cumprir o cronograma laboral.

Com a ausência de tempo para si, há a perda da subjetividade do professor, visto que o utilizaria livremente para pescar, ler, ouvir música, harmonizar com a família, praticar exercício físico, namorar, etc; muitas vezes gerando doenças como estresse, depressão, dependências químicas e ansiedade. Sintomas e consequências indignas a qualquer ser humano, ferindo o preconizado pelo artigo 170 da Constituição Federal.

Também, corroboram para a precarização do professor, a mercantilização do trabalho ideológico, visto que muitas vezes executam pesquisas por encomendas e produzem de acordo com o que é exigido pelo mercado, possuindo metas de publicações e promoções de eventos acadêmicos. 
Neste processo, o professor se insere como um meio para atingir um fim determinado pelo mercado, não tem liberdade para criar ou para utilizar seu tempo de vida, portanto o Direito ao Lazer, embora regulamentado, não é praticado. 0 tempo de vida do professor confundido ou muitas vezes é somente o tempo de trabalho, e um trabalho que lhe é estranho e externo.

\section{Referências}

ALVES, Giovanni. Trabalho e estranhamento: saúde e precarização do homemque-trabalha. São Paulo: LTr, 2012.

Dimensões da Precarização do trabalho: ensaios de sociologia do trabalho. Bauru: Canal6, 2013.

Anuário Estatístico. Universidade Estadual Paulista "Júlio de Mesquita Filho". - vol. 1(2001) -. - São Paulo: UNESP, APE, 2011. Disponível em: https://ape.unesp.br/anuario/index.php. Acesso em; 13 jun. 2014.

BACAL. Sarah. Lazer e o Universo dos Possíveis. São Paulo: Aleph, 2003.

BOSI, A. P. A precarização do trabalho docente nas instituições de ensino superior do Brasil nesses últimos 25 anos. Educação e Sociedade. Campinas, v.28, n.101, p. 1503-1523, set./dez. 2007.

BRASIL. Constituição (1934). Constituição da República Federativa do Brasil Disponível em: http://www.planalto.gov.br/ccivil_03/constituicao/constituicao 34.htm. Acesso em: 13 jun. 2014.

. Constituição (1988). Constituição da República Federativa do Brasil São Paulo: Saraiva, 2003a.

. CLT - Consolidação das Leis do Trabalho. São Paulo: Saraiva, 2003b.

CHESNAIS, François. A mundialização do Capital São Paulo: Xamã, 1996.

DUMAZEDIER, Joffre. Lazer e Cultura Popular. São Paulo: Perspectiva, 1973.

HYPOLITO, Álvaro Moreira; VIEIRA, Jarbas Santos; PIZZI, Laura Cristina Vieira. Reestruturação curricular e autointensificação do trabalho docente. Currículo sem Fronteiras. v.9, n.2,Jul/Dez 2009. Disponível em: http://www.curriculosemfronteiras.org/vol9iss2articles/hypolito-vieirapizzi.pdf. Acesso em: 20 jun. 2014.

MARCELLINO, Nelson Carvalho. Lazer e educação. $3^{\underline{a}}$ ed. Campinas: Papirus, 1995. 
MARTINS, Sergio Pinto. Comentários à CLT. 13ª ed. São Paulo: Atlas, 2009.

MARX, Karl. Manuscritos econômicos-filosóficos in: FROMM, E. Conceito Marxista do homem. Trad. Octávio A Velho. Rio de Janeiro: Zahar, 1967.

Elementos Fundamentales para la critica de la economia politica (borrador) 1857-1858 [Grundrisse]. Buenos Aires: Siglo XXI Argentina Editores, vol.2, 1973. MEDEIROS, Ethel Bauzer. 0 lazer no planejamento urbano. Rio de Janeiro: FGV, 1971.

MÉSZÁROS, István. Para além do Capital Campinas: Boitempo editorial, 2002.

NAVARRO, V. Trabalho, saúde e tempo livre sob os domínios do capital in PADILHA, V.(org.) Dialética do lazer. São Paulo, 2006.

NEGRI, Antonio e LAZZARATO, Maurizio. Trabalho Imaterial Rio de Janeiro: DP\&A, 2001.

REQUIXA, Renato. Sugestões de diretrizes para uma política nacional de lazer. São Paulo: SESC, 1980.

RUSSEL, Bertrand. 0 elogio ao Ócio. Rio de Janeiro: Sextante, 2002.

ROSSO, Sadi Dal. Mais trabalho: a intensificação do labor na sociedade contemporâneo. São Paulo: Boitempo, 2008.

SANT'ANA, Raquel Santos (Orgs.); LOURENÇO, Edvânia; NAVARRO, Vera, BERTANI, Iris; SILVA, José F.S. da. 0 Avesso do Trabalho II. 1aㅡ ed. São Paulo: Expressão Popular, 2010.

SANTOS, L. L. de C. P. formação de professores na cultura do desempenho. Educ. Soc., Campinas, vol. 25, n. 89, p. 1145-1157, Set./Dez., 2004.

SILVA, E.P.; SILVA JR, J.R. Estranhamento e desumanização nas relações de trabalho na instituição universitária pública. Revista HISTEDBR On-line. Campinas, número especial, p. 223-238, 12 fev. 2013.

SILVA JÚNIOR, João dos Reis.; SUISSARDI, Valdemar. Trabalho intensificado nas federais: pós-graduação e produtivismo acadêmico. São Paulo: Xamã Editora, 2009.

Recebido: 15/12/2014

Received: 12/15/2014

Aprovado: 19/12/2014

Approved: 12/19/2014 